\title{
LA REMODELACIÓN DEL CENTRO COMERCIAL DE SANTA CRUZ DE TENERIFE A MEDIADOS DEL SIGLO XX (1957-65): GOBIERNO MUNICIPAL, PROPIETARIOS Y COMERCIANTES
}

\author{
Luz Marina García Herrera \\ Departamento de Geografía e Historia. \\ Universidad de La Laguna (Canarias)
}

\begin{abstract}
Resumen: El artículo analiza la intervención del gobierno municipal de Santa Cruz de Tenerife, en las décadas de 1950 y 1960, en la remodelación de un sector del centro comercial, mediante una propuesta de Reforma Interior, y las reacciones de los distintos agentes urbanos afectados. La reforma, ejecutada en unas calles de elevada valoración y residencia de familias muy prósperas, originó un gran aumento de la volumetría acompañado por una revalorización inmobiliaria, expulsó a los arrendatarios modestos, y propició una reestructuración del comercio, unida a la incorporación de nuevos grupos sociales en la zona.
\end{abstract}

Palabras clave: Gobierno municipal, Centro comercial, Plan del Cuadrilátero, Propietarios, Comerciantes, Santa Cruz de Tenerife.

The renewal of Santa Cruz de Tenerife' commercial downtown in the mid-twentieth century (19571965): urban government, landowners and merchants

Abstract: The paper analyzes the intervention of Santa Cruz de Tenerife urban government, between mid1950s and mid-1960s, in the redevelopment of one section of the commercial downtown, through an urban renewal project, and the reactions by the different agents concerned. The renewal, which was realized on highly-valued streets and home of well-to-do families, resulted in a large increase of built space as well as a real estate revalorization; a restructuring of trade took place, once the small tenants were evicted, together with the incoming of new social groups in the area.

Key words: Urban government, Downtown, Plan of Cuadrilátero, Landowners, Merchants, Santa Cruz de Tenerife.

\section{INTRODUCCIÓN}

A mediados del siglo XX la producción del espacio urbano en España estaba muy condicionada por el dominio de los intereses inmobiliarios, basados en la renta del suelo; la actividad urbanística, nos dice García Bellido (1998-99), aún no había realizado la revolución liberal. La aprobación de la Ley del Suelo de 1956 sancionó la experiencia legisladora previa, confirmando un intervencionismo estatal protector de los intereses de la propiedad territorial, al tiempo que incorporó elementos de planeamiento vinculantes y jerárquicos del modelo mussoliniano, según el mismo autor. Entre los rasgos que definen la excepcionalidad del modelo urbanístico español en el ámbito europeo interesa aquí desta-

Data de recepció: 19 de novembre de 2014 / Data d'acceptació: 14 de gener de 2015. 
car los ingentes derechos que otorga a la propiedad del suelo, que se apropia de los beneficios garantizados por el planeamiento por definición legal, al tiempo que establece un conjunto de deberes de manera prescriptiva (como los plazos para urbanizar y edificar) (García Bellido, 1998-99 y 2005).

En el planeamiento urbano español de la década de 1950, e incluso de los años sesenta, el tratamiento de los cascos antiguos se caracterizó por proponer o mantener operaciones de reforma interior, típicas de la centuria anterior, consistentes en la apertura de nuevas vías o ampliación de las existentes (Burriel, 2009; González Pérez, 2005; Tatjer Mir, 1988 y 2000); las actuaciones de los años cincuenta, en el precario contexto económico de la política autárquica, se limitaron a operaciones puntuales sobre áreas concretas de los centros históricos, como fue el caso de Barcelona (Tatjer Mir, 2000). La década de los sesenta, en cambio, estuvo marcada por las políticas urbanas del desarrollismo económico, fruto del Plan de Estabilización de 1959 y la apertura al exterior, un período en el que los grupos inmobiliarios, plantean actuaciones de mayor alcance espacial. El núcleo de la ciudad desarrollista se convirtió, en gran medida, en el escenario de una importante actividad constructiva que se desplegó tanto en el casco antiguo y sus bordes como en el ensanche del XIX, o en el espacio entre ambos; son los años de propuestas de remodelación de gran impacto tanto en la ciudad vieja como en los bordes (Tomé Fernández, 2012; Tatjer Mir, 2000). La obtención de rentas diferenciales, derivadas de la localización y de la inversión de capital, estimuló la transformación de los espacios centrales, especialmente de determinadas vías de gran relevancia.

Una amplia parte de los cascos antiguos conservaba aún las funciones de centralidad por lo que su actividad mercantil mantenía una potencia muy destacada; a ello se añade que en la posguerra las ciudades medias experimentaron reformas que supusieron un cambio fisonómico de las principales vías urbanas y comerciales, y en algunos casos también les confirieron mayor peso. En los núcleos principales del comercio se concentraban las tiendas de uso poco frecuente, conviviendo con establecimientos más básicos; una de las características del entramado comercial era la dualidad entre el modesto comercio dominante y un contado comercio de lujo que expresaba el clasismo de la época, si bien en las ciudades con un régimen de puertos francos estos rasgos generales se matizaron en función de la presencia de comunidades étnicas con establecimientos comerciales y sistemas de importación peculiares. A lo largo de los años sesenta se produjo una importante expansión del comercio cuyos preludios se encuentran en el moderado desarrollo de las cadenas comerciales y la difusión del gran comercio local, con un tamaño y rasgos organizativos que las acercaban al tipo de grandes almacenes (Tomé Fernández, 2013). En este sentido se ha señalado la relación entre las políticas de remodelación urbana y la subsecuente reestructuración comercial mediante la instalación de nuevos tipos de establecimientos en el centro de la ciudad (Tomé Fernández, 2012).

En este artículo se estudia el caso de una ciudad media, Santa Cruz de Tenerife, en las décadas de 1950 y 1960, con objeto de conocer, en un marco institucional muy jerárquico y autoritario, la actuación del gobierno local en la transformación de un área significativa del centro urbano. El análisis aborda la propuesta e intervención del gobierno municipal en la Reforma Interior de un amplio sector del centro comercial, denominado el Cuadrilátero; las reacciones de los agentes urbanos afectados por la operación y las consecuencias de carácter urbanístico, comercial y social que la acompañaron.

Las principales fuentes consultadas han sido el Expediente General del Plan de Mejora Interior del Cuadrilátero, custodiado en la Gerencia de Urbanismo, y los Libros de Actas 
del Pleno del Ayuntamiento para el período 1959-65. La investigación se apoya en la documentación contenida en el expediente municipal que, complementada con las actas, ha permitido obtener la información relativa a los inmuebles y propietarios afectados, seguir las vicisitudes del proceso administrativo y reconocer las actitudes de los distintos actores.

\section{"EL CUADRILÁTERO": LA REFORMA DEL CENTRO COMERCIAL DE SANTA CRUZ DE TENERIFE}

La actividad económica de Santa Cruz de Tenerife, desde su fundación, se desarrolló en torno al tráfico del puerto, de modo que la actividad portuaria constituía su base económica; el dinamismo comercial de la ciudad, que en 1950 daba empleo a más de la cuarta parte de los activos del sector servicios $(26,6 \%)$, aún estaba profundamente vinculado al movimiento de pasajeros del puerto (Murcia Navarro, 1975).

A principios de los años cincuenta, la ciudad histórica monopolizaba la localización del comercio que se concentraba de manera muy destacada en el centro urbano, en un ámbito que se extendía desde las calles inmediatas al puerto hasta la Plaza Weyler y el barrio del Toscal; la presencia del comercio indio, sus típicos bazares, caracterizaba la calle del Castillo, Plaza de la Candelaria y su entorno; se trataba de establecimientos destinados a los grupos más adinerados de la sociedad canaria y a la clientela siempre renovada constituida por los pasajeros de los buques en tránsito (López Sala y Esteban Sánchez, 2010, 149-150).

Además del movimiento portuario y del comercio asociado, el turismo comenzaba a destacar como un tercer renglón económico, si bien contaba con antecedentes pues los cruceros frutero-turísticos habían vinculado a las islas, desde las primeras décadas del siglo XX, al movimiento turístico atlántico y mediterráneo. La recuperación del tráfico de pasajeros, desde mediados de la década de los cincuenta, suscitó expectativas sobre el posible desarrollo turístico de la ciudad que fue activamente impulsado por los diferentes gobiernos locales a lo largo de los años sesenta, en el marco del proceso de apertura al exterior del régimen franquista (aprobación del Plan Parcial de la playa de Las Teresitas en 1961 y su declaración como CITN en 1967, proyectos de hoteles, etc).

En 1957 se aprobó el Plan General de Ordenación que incorporaba la ejecución de varios proyectos de Reforma Interior para la ciudad histórica; su objetivo era mejorar la accesibilidad al centro, además de crear un segundo polo comercial e institucional en el frente marítimo.

Estos planes formaban parte de la política municipal dirigida a impulsar la actividad comercial y turística, relacionada con el movimiento de pasajeros del puerto. La viabilidad de tal propósito político-económico demandaba una reorganización espacial de la ciudad.

Así uno de estos proyectos planteaba la remodelación del centro tradicional del comercio, afectando a una superficie de cinco hectáreas comprendida en el cuadrilátero delimitado por las calles de Bethencourt Alfonso, Valentín Sanz, Suárez Guerra, Emilio Calzadilla y La Marina (Figura 1). La renovación del Cuadrilátero, en paralelo a la postergada ejecución del Plan Parcial de Urbanización del sector de la Avenida Marítima y zona adyacente, habría completado la aspiración falangista de configurar un espacio urbano en el frente marítimo "que sirviendo de entrada a la ciudad exprese la fuerza y la misión de España" (Rumeu y Cabrera, 1953, 57; García Herrera y Smith, 2004). 


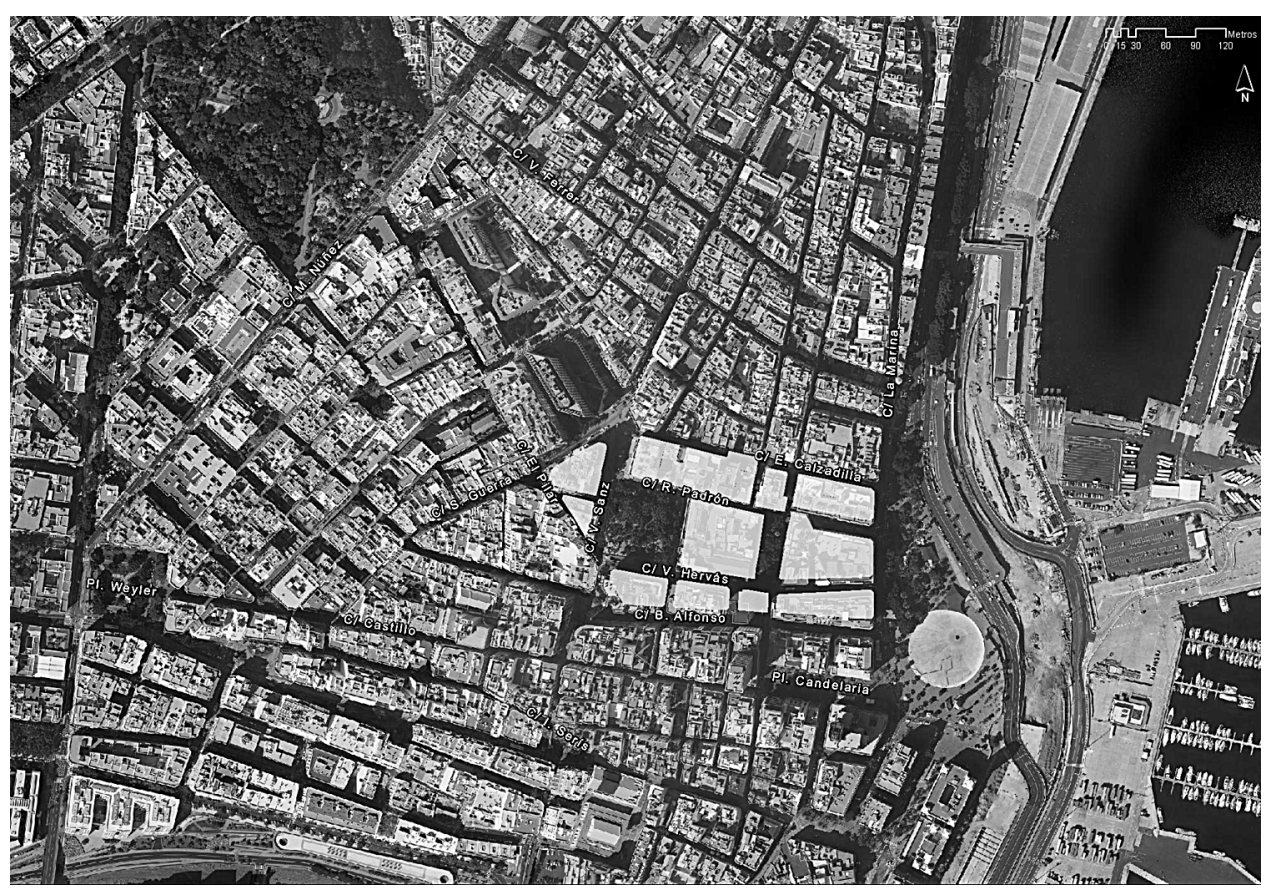

Figura 1. Centro comercial de Santa Cruz de Tenerife. En los primeros años de la década de 1950 gran parte de la actividad se concentraba en el ámbito comprendido entre el puerto, la Plaza Weyler y la calle San Vicente Ferrer. La Reforma Interior del Cuadrilátero remodeló un sector amplio y relevante, generando una reestructuración comercial. Fuente: Grafcan ortofoto express urbana 2012 (Elaboración: Alejandro Armas Díaz).

Las propuestas del Plan General se centraban de manera preferente en el centro urbano. Dada la diferenciación social del espacio en dos sectores: el área urbanizada próxima al puerto y una extensa periferia ocupada por fincas rústicas, barrios de autoconstrucción y algunas viviendas públicas, la reedificación del ámbito más central generaría importantes rentas diferenciales para los poseedores de suelo e inmuebles.

El denominado 'Plan del Cuadrilátero' proponía el trazado de una vía rápida que atravesaba la zona comercial mejor situada, con el objetivo de facilitar el acceso desde el entorno portuario hacia la parte alta de la ciudad. La renovación morfológica también sirvió para incorporar al área comercial varias calles laterales ocupadas por construcciones bajas, como Pilar y Villalba Hervás (Tomé Fernández, 2012).

\section{LA PROPUESTA MUNICIPAL: DE LA COOPERACIÓN A LA EXPROPIACIÓN}

El acceso directo del tráfico rodado desde el puerto hacia la zona interna de la ciudad -uno de los objetivos de la reforma- se lograba mediante la apertura de una vía rápida 
a través del centro urbano. En torno a la propuesta concreta para su ejecución, se produjo una discrepancia entre los que defendían la necesidad de transformar la calle Bethencourt Alfonso hasta su encuentro con la calle del Pilar, opción que requería una ejecución lenta y muy costosa por su carácter eminentemente comercial; y aquellos que propugnaban la ampliación de la calle paralela, Villalba Hervás, sin comercios y, por tanto, de ejecución rápida y barata. Los segundos recomendaban que la actuación de Bethencourt Alfonso se dejara a la iniciativa privada debido al elevado coste y plazo de realización.

Sin embargo el Ayuntamiento, en enero de 1956, acordó la reforma más lenta y costosa al considerar que la ampliación de la calle Bethencourt Alfonso, junto con la de Emilio Calzadilla, eran piezas clave en la creación de un tráfico tangencial al centro comercial que facilitara la comunicación entre la Plaza Weyler, en el interior, y el puerto. Meses más tarde aprobó el Plan de Mejora Interior del Cuadrilátero (24/8/1956), con un coste total de 80.609 .993 pesetas, dedicándose el $83 \%$ de dicho importe a pagar las expropiaciones, mientras que las indemnizaciones estimadas apenas alcanzaban el 3\%. Asimismo tres cuartas partes del gasto total se concentraban en la reforma de tres calles (Bethencourt Alfonso, Emilio Calzadilla y Ruiz de Padrón).

Se presentaron 128 alegaciones para un conjunto de 116 parcelas que expresan, teniendo en cuenta el régimen autoritario del momento, una considerable contestación social tanto de los afectados por las reformas (propietarios y arrendatarios) como de diversas instituciones corporativas. La Comisión de Obras desestimó las alegaciones, argumentando que los propietarios de comercios en el Cuadrilátero iban a alcanzar grandes beneficios y que mediante acuerdos con éstos podía minimizarse el aumento de la presión fiscal.

Seis meses más tarde, en junio de 1957, se aprobó el Programa de Actuación que se ejecutaría en diez años (1958-67); en el primer quinquenio se realizarían las reformas de Bethencourt Alfonso y de Villalba Hervás; en el segundo los restantes proyectos. El sistema de ejecución sería el de Cooperación, declarándose las obras del polígono de interés inmediato. A los propietarios se les instaba a decidir, en el plazo de dos meses, si aceptaban o no la cooperación; transcurrido ese período, si los cooperantes representaban menos del $60 \%$ de la superficie o del valor de los terrenos, como establecía la Ley del Suelo de 1956, el Ayuntamiento los expropiaría procediendo a su urbanización y posterior venta.

En uso de sus facultades prescriptivas, el Ayuntamiento determinó que los propietarios debían demoler los edificios en el plazo de un año y terminar las nuevas construcciones antes de cuatro. Estas debían alcanzar al menos 5 plantas, con una altura mínima de $18 \mathrm{~m}$, lo que significaba la desaparición de la mayor parte de los inmuebles existentes, entre una y tres alturas, al tiempo que obligaba a los propietarios a un desembolso considerable. Las exigencias a los propietarios se compensaban con facilidades para su financiación, como anticipos reintegrables "para estimularles a la rápida edificación de los solares resultantes", al tiempo que la corporación se comprometía a solicitar los beneficios fiscales contemplados en la Ley del Suelo. En cambio el Programa de Actuación no mencionaba las indemnizaciones a los arrendatarios de viviendas y negocios.

Como ha señalado García Bellido (1982, 51), el sistema de Cooperación implicaba la financiación íntegra de la operación por el Ayuntamiento "quien adelanta el costo de la obra urbanizadora, cobra los gastos estrictos y no se apropia de ningún sobrebeneficio por ella creado con la urbanización y el plan, entregando los solares, aptos para la especulación privada y apropiación de todas las rentas, a los propietarios iniciales". Mediante la propuesta inicial de ejecutar la reforma con el sistema de cooperación los mandatarios lo- 
cales conservaban la iniciativa política del proceso, obtenían los terrenos de uso público y aportaciones económicas de los propietarios al tiempo que los incentivaban mediante la concesión de anticipos y, sobre todo, la expectativa de disfrutar de una bonificación fiscal durante un largo período, al plantear el plazo máximo de 25 años contemplado en la Ley del Suelo.

El plan fue aprobado definitivamente por el Ministerio de la Vivienda el 23 de diciembre de 1957. Poco después, más del 60\% de los propietarios aceptaron el sistema de cooperación, pero un buen número establecía condiciones exigiendo contrapartidas al Ayuntamiento. Por un lado, pedían incluir en el justiprecio de las propiedades afectadas las indemnizaciones correspondientes a los desahucios de viviendas y de locales de negocios, esquivando así el derecho de los arrendatarios a ser readmitidos en el nuevo edificio (según la vigente Ley de Arrendamientos Urbanos), cuestión que tendría que dirimirse en los tribunales; por otro, exigían, además de la bonificación fiscal aplicable a las nuevas construcciones durante un máximo de 25 años, que se les indemnizase por el derribo de los edificios existentes.

En este caso los valores autoritarios del franquismo marcaron absolutamente la decisión municipal: "La Corporación no puede computar como tal aceptación, .../..., las aceptaciones condicionales, .../... La aceptación de la cooperación es un contrato de adhesión..." (cursiva nuestra). En consecuencia, al descontar los escritos condicionados, no se alcanzó el 60\% requerido por el artículo 118 de la Ley del Suelo y por la base quinta del Programa de Actuación.

La decisión definitiva se acordó en el pleno del 24 de julio de 1958 desestimándose la cooperación colectiva, de modo que el Ayuntamiento optó por la expropiación de los inmuebles pero ofreció a los propietarios la posibilidad de evitarla si se acogían incondicionalmente a la cooperación individual. La Corporación aprobó, asimismo, las nuevas valoraciones que elevaron el coste total del proyecto a 85.683.134,52 pesetas.

La decisión municipal estaba guiada por el principio de no limitar la iniciativa privada y era similar a la adoptada, unos meses antes, en otra área sujeta al sistema de expropiación en el sector de La Salle (21/3/1958), en la inmediata periferia, cuyos terrenos deberían constituir el Patrimonio Municipal del Suelo; sin embargo, el Ayuntamiento ofreció exceptuar de la expropiación, a cambio de una serie de ventajas fiscales, a los propietarios que se comprometiesen a urbanizar en los plazos establecidos y financiar los costes de infraestructuras (García Herrera, 1989, 91).

\section{LOS DISTINTOS INTERESES ECONÓMICOS: COMERCIANTES, PROPIETARIOS Y ARRENDATARIOS}

Del conjunto de alegaciones presentadas en 1956 se ha analizado una muestra de siete reclamaciones cuya finalidad es ilustrar la diversidad de posiciones entre los agentes urbanos; así se presentan las de las Cámaras de la Propiedad Urbana y de Comercio, y las de otros afectados de diferente posición social (medianos y pequeños comerciantes, grandes propietarios, arrendatarios de locales).

Desde la perspectiva de los comerciantes, la propuesta de remodelación situó a la Cámara Oficial de Comercio, Industria y Navegación de la Provincia en el "franco terreno de la oposición”. En la alegación que presentó manifestaba su preocupación por los locales 
de negocio, quejándose de las exiguas indemnizaciones con las que "no se puede hacer frente a un traslado de negocio, ni siquiera con otra, de cuantía veinte veces superior"; señalando además la asimetría entre la cantidad total destinada a indemnizaciones para los afectados de las calles Bethencourt Alfonso y Valentín Sanz (1.530.800 pesetas), y la asignada a las vías restantes (938.100 pesetas).

Enumeraba en 177 los locales perjudicados por la reforma, que daban empleo a 1.412 trabajadores (que con sus familias alcanzaban 7.150 personas, el 6,9\% de la población de la ciudad), y calculaba una pérdida mensual de 1.589 .000 pesetas, en un momento de incertidumbre económica y emigración. Asimismo sugería que se desarrollase primero la zona comercial prevista en el Plan Parcial de Urbanización del sector de la Avenida Marítima, y después se interviniese en el sector del Cuadrilátero. E introducía una crítica al Ayuntamiento indicando que debía renunciar a los solares resultantes, "lo que equivale también, a renunciar a un lucrativo negocio municipal".

En cuanto a los medianos y pequeños comerciantes, sus reparos consistieron en pedir un notable aumento de las indemnizaciones asignadas. Su demanda se orientaba a lograr del Ayuntamiento criterios de valoración más altos.

En suma, los comerciantes, con independencia del tamaño de su negocio, reclamaron un aumento en las compensaciones. En sus escritos expresaban la privilegiada situación de los establecimientos, aludiendo además a otros factores como los nuevos precios de los locales comerciales, su escasez, la pérdida del derecho de traspaso, inactividad forzada, indemnizaciones a sus empleados y gastos de la nueva instalación.

Por su parte, los poseedores de inmuebles, un conjunto de 73 propietarios de 79 parcelas e inmuebles, constituían una amplia representación de familias acaudaladas y relevantes de la ciudad; algo más de la quinta parte de ellos, al menos, tenía su domicilio en zona distinta al Cuadrilátero. En el conjunto, compuesto por una muestra significativa de linajes importantes de la capital y de la isla de Tenerife, figuraban miembros de los grandes apellidos propietarios desde la colonización, significados prestamistas, empresas consignatarias o de transportes, además de un buen grupo de familias de la clase alta o media alta santacrucera.

En relación con la propuesta municipal, la Cámara Oficial de la Propiedad Urbana de la Provincia planteó diversas objeciones a la vez que pedía la nulidad del Plan Parcial salvo que en él se incorporasen sus sugerencias. Las consideraciones sustanciales reclamaban un aumento en las valoraciones tanto de solares como de edificios; el establecimiento de un sistema de actuación que permitiera a los propietarios de los vacíos resultantes utilizarlos; que la ampliación de la calle Emilio Calzadilla afectase sólo al lado de los números impares, y la construcción de viviendas antes de iniciar las demoliciones para evitar un "importantísimo problema social" provocado por el aumento en la demanda habitacional.

Los planteamientos de ambas Cámaras, de Comercio y de la Propiedad Urbana, incorporaban además algunas consideraciones de carácter legal; las dos instituciones objetaron la aprobación de un plan parcial sin previa aprobación definitiva del plan general; el incumplimiento municipal de la Ley del Suelo (artículos 10, 109, 108 y 110; y capítulo IV del Título II) y la ausencia del estudio económico-financiero preceptivo.

Respecto a los grandes propietarios de parcelas (y también de negocios en algunos casos), la réplica se centró en el elevado valor que tenía el $\mathrm{m}^{2}$ del sector más importante de la capital señalando que ".../... (se deben) contrapesar cuidadosamente las necesidades urbanísticas y el valor del metro cuadrado de superficie afectada”. 
Revestido de un contra argumento urbanístico que rechaza la propuesta municipal (debido al ancho excesivo para cruce directo de peatones, muchas vías en poca superficie, la escasa relación entre aceras y calzadas, etc.) llevan su oposición a la "innecesaria disminución de la superficie de solares" así como a un "aumento innecesario de las obras de pavimentación, alcantarillado, conducciones de agua,.../..." e igualmente solicitan un aumento de las valoraciones e indemnizaciones.

El tercer grupo afectado por la reforma fue el de los inquilinos y arrendatarios de locales. Las referencias concretas a los inquilinos de viviendas son muy escasas en las fuentes manejadas, por lo que nos consta sólo la existencia de 31 situaciones de arrendamiento y alquiler en 14 inmuebles de las calles Bethencourt Alfonso y Villalba Hervás. En cuanto a los locales comerciales arrendados, de los 29 para los que podemos documentar la actividad desempeñada, la mayoría se califican como locales de negocio; entre ellos aparecen los dedicados a un comercio básico (mercerías), servicios comerciales-artesanos (zapatería, barbería, sastrería), alguna tienda-taller (taller de relojería), una imprenta, o un estanco de tabaquería, comercio vinculado a la condición insular de Puertos Francos (Tomé Fernández, 2013).

Desde que se inició el proceso de negociaciones con el Ayuntamiento para integrarse en el sistema de cooperación, los propietarios pidieron que, en el justiprecio, se incluyera la indemnización a satisfacer a sus inquilinos por el desahucio de las viviendas y locales arrendados; mediante esa vía, la de la indemnización municipal, su propósito era eludir el derecho de sus arrendatarios a ser readmitidos en el nuevo edificio, tal como establecía el artículo 78 y siguientes de la (entonces vigente) Ley de Arrendamientos Urbanos, espinosa cuestión que podía llevarles a un procedimiento judicial.

Pero al optar por el sistema de expropiación, el Ayuntamiento, de acuerdo con la Ley de Bases del régimen local de 1945, asumió, al igual que ocurría en otras ciudades, los costes de indemnización de los inquilinos y arrendatarios de locales (Tatjer Mir, 2000, 18). Cabe señalar que constan abundantes situaciones en las que los arrendatarios no recurrieron pero se resistieron a la acción municipal, eludiendo el acuerdo amistoso, la presentación de valoraciones, y demorando el procedimiento hasta producirse la orden de desahucio. Entre los arrendatarios de locales, sólo 9 presentaron recurso al Jurado Provincial de Expropiación, llegando en un caso al contencioso-administrativo. En estos casos sus negocios debieron de ser importantes como cabe deducir de la decisión de afrontar una acción judicial y de las indemnizaciones obtenidas.

En relación con las indemnizaciones a comercios e industrias, el Ayuntamiento conocía la situación que reflejaban estas reclamaciones pues la Comisión de Obras, en escrito del 30/11/56, informó que las valoraciones efectuadas eran estimaciones iniciales; de igual modo el Arquitecto Jefe reconocía, en mayo de 1957 que "se ha operado más bien sobre las rentas que abonan por sus locales.../... la cifra ... para indemnizaciones resulta insuficiente y ... deberá ser corregida".

\section{LA REMODELACIÓN DEL SECTOR}

El proyecto de reforma generó un efecto de revalorización en el área, como puso de manifiesto un informe de la Sección de Arquitectura que admitía la acusada revalorización experimentada en el breve plazo de dos años, de 1956 a 1958, destacando el incre- 
mento del precio del suelo en las calles Bethencourt Alfonso (40,6\%), Villalba Hervás y Ruiz de Padrón (14\% ambas), algo menos en Emilio Calzadilla (11\%) y Suárez Guerra (8\%). Revalorización que se apropiarían privadamente los dueños del suelo sin ninguna participación por la colectividad, pues la vía fiscal prevista por la Ley del Suelo resultó insuficiente a todas luces.

El nuevo valor adquirido por la zona a remodelar debió de estimular la actividad de los propietarios ante la posibilidad de obtener importantes rentas diferenciales dadas la centralidad, accesibilidad y usos del Cuadrilátero. Ya que una vez que las alegaciones fueron desestimadas, éstos se incorporaron con prontitud a la vía de la cooperación individual, ofrecida por el Ayuntamiento. De modo que, en poco más de año y medio, la mayor parte de los propietarios se habían acogido al sistema de cooperación: 33, es decir tres cuartas partes de los afectados de la calle Bethencourt Alfonso, y 10 -dos tercios- de la de Villalba Hervás. Con posterioridad se recibieron nuevas solicitudes de cooperación, si bien desconocemos su número exacto.

Respecto a los inquilinos, los propietarios estaban interesados en expulsar a los ocupantes de los inmuebles a derribar pero su desalojo tuvo que ser un problema que retrasó la ejecución del plan y, sobre todo, debió constituir un problema social con cierta repercusión. Así, en 1960 alguno de ellos señalaba la imposibilidad de comenzar las obras del nuevo edificio hasta que el Juzgado desalojase a los inquilinos.

Aún así, en mayo de 1957 ya "han sido reconstruidos nuevos edificios en la alineación oficial", es decir, la señalada por el Plan del Cuadrilátero. Además de unos pocos propietarios que habían edificado con anterioridad al Plan de Mejora Interior, conocemos algunas situaciones en las que éstos actuaron con rapidez demoliendo y construyendo de nueva planta. No obstante, su relación con el Ayuntamiento no estuvo exenta de fricciones. Fue el caso de pequeños propietarios que, mediante una estrategia de valoración individual, habían recurrido a la licencia de construcción, adaptándose a las alineaciones establecidas por el Plan General de 1957, para renovar sus inmuebles antes de la reforma del Cuadrilátero, y reclamaban ser indemnizados por el derribo ya efectuado; o el de varios propietarios relevantes a los que el Ayuntamiento advertía aún en 1965, tras sucesivas notificaciones y prórrogas, de la necesidad de derribar su inmueble o de comenzar la reedificación, bajo amenaza de expropiación.

Un buen número de propietarios tuvo que asociarse con otros para acometer la nueva edificación; situación que hemos documentado en 19 ocasiones (que representan un 23\% del total). Asimismo, algunos intentaron cumplir el requisito de altura exigido por el plan, sin derribar la construcción sino "comprometiéndose a levantar sobre el edificio existente las crujías precisas para alcanzar la altura mínima de 18 metros". Por último, otro grupo de once optó por vender sus inmuebles. Por lo que, aunque se verían beneficiados por las rentas diferenciales derivadas de la privilegiada localización, parece que un sector de propietarios no alcanzaba el umbral de inversión requerido para la renovación. Una escasa capacidad económica que, en esos años, imposibilitó la actuación de los propietarios y promotores locales en otra Reforma Interior, la de la Avenida Marítima (García Herrera y Smith, 2004, 127).

Por su parte, los pequeños arrendatarios conocieron situaciones de especial dificultad, que quedaron reflejadas en sus alegaciones, y que posiblemente contribuyeron a la paulatina sustitución de los comercios tradicionales en la zona. Tomé Fernández (2012) ha señalado, con carácter general, el desajuste entre los rendimientos del pequeño comercio de 
carácter familiar, o incluso tiendas medianas, y los beneficios potenciales de sus locales en vías muy valoradas en el mercado inmobiliario, que conduce a su cierre o traslado fuera del área. El aumento, y diversificación, de los establecimientos comerciales así como de oficinas y despachos profesionales en la calle Bethencourt Alfonso (Murcia Navarro, 1975, 227); o la presencia de Galerías Preciados, cadena de grandes almacenes, instalada ya en 1975 en el borde del Cuadrilátero (Tomé Fernández, 2012) apuntan a un proceso de reestructuración comercial impulsado por la Reforma Interior.

El Plan del Cuadrilátero implicó no sólo una transformación morfológica, y en cierto sentido social. También convirtió la calle Bethencourt Alfonso en uno de los principales ejes comerciales de Santa Cruz de Tenerife, y uno de los más valorados. En este sentido la compraventa de inmuebles propició además la entrada de los comerciantes indios en la zona, como apuntan algunos casos en la mencionada calle, que hacia 1970 presentaba la mayor concentración de bazares de la ciudad, así como un peso destacado de los directivos y empleados del comercio indio entre la población extranjera residente en dicha vía (Murcia Navarro, 1975, 227). La importancia de esta comunidad resulta coherente con el intenso flujo inmigratorio registrado hacia Canarias desde finales de los años cincuenta; se trataba de comerciantes procedentes de India y otros puntos del mundo, que llegaban atraídos por las oportunidades de negocio representadas por los puertos francos (López Sala y Esteban Sánchez, 2010, 150-151). Establecidos junto a los puertos, concentraron igualmente su residencia en los ámbitos centrales próximos.

En suma, el Plan de Mejora Interior remodeló el conjunto del Cuadrilátero que, a principios de la década de 1970, ofrecía, en sus arterias principales, un paisaje de edificios nuevos, de entre 6-9 plantas, con una estructura de la propiedad concentrada, y en los que predominaba el uso de oficinas y comercios sobre el residencial (Murcia Navarro, 1975, 220-223).

\section{CONCLUSIONES}

La Reforma Interior del Cuadrilátero confirma la relevancia de los gobiernos locales, y especialmente bajo un régimen autoritario, en la producción del espacio urbano, bien mediante la expansión geográfica de la ciudad, bien mediante la re-diferenciación del espacio ya construido, como en el caso analizado. De las cuatro Reformas propuestas en el Plan General, la remodelación de un sector del centro comercial fue la única que se efectuó con bastante rapidez, pues dos de ellas no se realizaron hasta las últimas décadas del siglo XX; y una tercera se prolongó en el tiempo, generando un ámbito de creciente degradación hasta la segunda mitad de los años noventa.

La presteza con que se produjo la renovación contrasta con la demora en otros sectores urbanos sujetos al sistema de expropiación, como fueron La Salle o el ámbito de la Avenida Marítima. En el primero, los propietarios y el Ayuntamiento tardaron más de una década en impulsar su edificación, inacción en la que el cálculo de obtener importantes rentas diferenciales por parte de los propietarios y la carencia (crónica) de recursos económicos por parte de la Administración municipal para abordar su ejecución tuvieron que desempeñar un papel destacado; mientras en el segundo, la realización del Plan Parcial de la Avenida Marítima (1958), debido a la ineficacia y excesiva discrecionalidad de la actuación municipal, se prolongó durante tres décadas.

Desde una perspectiva social, la actuación del Ayuntamiento tuvo consecuencias claramente asimétricas, perjudicando en mayor medida a los grupos con menores recursos y 
capacidad de presión; rasgos que se repiten en la implementación de las distintas reformas interiores planteadas. La intervención en el Cuadrilátero afectaba a acaudaladas y relevantes familias de la ciudad que tenían su residencia, sus negocios, o ambos, en dichas calles, y su propuesta tuvo una amplia oposición tanto de los propietarios como de los comerciantes. Desde la óptica de sus intereses como grupo social, las familias dueñas de los inmuebles permanecieron en el sector y acabaron beneficiándose, a medio plazo, del aumento de valor de sus propiedades. Así mientras la mayor parte de la clase media-alta se reasentó en la zona o en barrios céntricos, los inquilinos y arrendatarios modestos, por el contrario, fueron expulsados perdiendo las ventajas de la localización.

En conjunto, la remodelación, que se produjo en un área destacada y de elevada valoración, originó un gran aumento de la volumetría en las calles ordenadas, seguido por un incremento del valor del suelo y de los inmuebles; revalorización que atrajo la entrada de nuevos capitales hacia el sector donde se intervino provocando un proceso de concentración fundiaria y de reestructuración comercial, acompañado de la incorporación de otras comunidades étnicas y grupos sociales de mayor renta.

\section{BIBLIOGRAFÍA}

BURRIEL DE ORUETA, E. (2009): "Planificación urbanística y ciudad" en: Hermosilla, J. (Coord.), La ciudad de Valencia. Historia, Geografía y Arte, Valencia, Universidad de Valencia, 144-171.

GARCÍA BELLIDO, J. (1982): "La especulación del suelo, la propiedad del suelo y la gestión urbanística”, Ciudad y Territorio, 3, 45-72.

GARCÍA BELLIDO, J. (1998-1999): "La excepcional estructura del urbanismo español en el contexto europeo", Documentación Administrativa, septiembre 1998-abril 1999, 252-253.

GARCÍA BELLIDO, J. (2005): "Por una liberalización del paradigma urbanístico español (III): el tsunami urbanístico que arrasará el territorio", Ciudad y Territorio/ Estudios Territoriales, 144, 273-288.

GARCÍA HERRERA, L.M. (1989): Propiedad del suelo en Santa Cruz de Tenerife. Secretariado de Publicaciones de la Universidad de La Laguna, $221 \mathrm{p}$.

GARCÍA HERRERA, L.M. y SMITH, N. (2004): "Planeamiento, desalojos e inversión inmobiliaria en El Cabo-Los Llanos (Santa Cruz de Tenerife)” en: Sánchez García, J. (ed.), Toma de decisiones colectivas y política del suelo, Fundación César Manrique, 121-138.

GONZÁLEZ PÉREZ, J. (2005): "Planificación y construcción de ciudades medias en el sistema urbano industrial: Los casos de Palma de Mallorca y Vigo", Boletín de la AGE, 40, 449-471.

LÓPEZ SALA, A.M. y ESTEBAN SÁNCHEZ, V. (2010): "Los comerciantes sindhis en Canarias. Relaciones transnacionales y actividad económica", Revista CIDOB d'Afers Internacionals, 92, 139-159.

MURCIA NAVARRO, E. (1975): Santa Cruz de Tenerife, un puerto de escala en el Atlántico, Aula de Cultura de Tenerife, $274 \mathrm{p}$.

RUMEU, E. y CABRERA, L. (1953): "Plan General de Ordenación Urbana de la ciudad de Santa Cruz de Tenerife", Revista de Arquitectura, 140-141, 57-74.

TATJER MIR, M. (1988): Burgueses, inquilinos y rentistas. Mercado inmobiliario, propiedad y morfología en el centro histórico de Barcelona: La Barceloneta, 1753-1982, Madrid, Consejo Superior de Investigaciones Científicas, $400 \mathrm{p}$.

TATJER MIR, M. (2000): "Las intervenciones urbanísticas en el centro histórico de Barcelona: de la Vía Laietana a los nuevos programas de revitalización” en: Bernal Santaolalla, B. (Coord.), 
Oportunidades de desarrollo sostenible para los conjuntos urbanos históricos, Burgos, Universidad de Burgos, 14-28.

TOMÉ FERNÁNDEZ, S. (2012): "Comercio y ciudades medias en la España del desarrollismo", Biblio3W. Revista bibliográfica de Geografía y Ciencias Sociales, vol. XVII, no 1003. Disponible en http://www.ub.edu/geocrit/b3w-1003.htm

TOMÉ FERNÁNDEZ, S. (2013): "Posguerra y ciudad, la memoria del comercio perdido", Ería, 91, 111-128. 